Philipp Kipp, Eva Alice Christiane Bittner, Ulrich Bretschneider, Jan Marco Leimeister

\title{
Collaborative elaboration of early innovation ideas
}

WBIP_Open Innovation_Collaboration Engineering_CSCW

Summary. Web-based innovation platforms (WBIP) are common tools for the integration of customers and other external stakeholders into the product and service innovation processes of companies. WBIP of many large companies are very successful in generating many ideas. This leads to WBIP operators drowning in lots of possibly creative and high potential ideas, which are difficult to screen. Therefore, this paper suggests a collaboration process allowing customers to participate collaboratively in the elaboration of self-selected ideas. The collaboration process has been developed following the collaboration process design approach and was designed to be implemented on WBIP.

\section{Introduction}

The trend to open up different aspects of the value chain combined with the rise of the internet as a simple way to communicate with a broad auditorium allows new forms of customer integration. Without current technology, customer integration has only been possible by interviewing small samples of lead users (von Hippel 2005) or conducting large standardized surveys. Web-based innovation platforms (WBIP) for implementing Virtual Idea Communities or online Idea Competitions now allow all customers to share their insights, opinions and ideas regarding a product with the manufacturer or other customers (Bretschneider, Huber et al. 2008). Popular WBIP such as Dell Ideastorm ${ }^{1}$, Innocentive ${ }^{2}$ or My Starbucks Idea ${ }^{3}$ and many other platforms were developed by companies trying to get their customers to generate many innovative ideas. Ideas generated on these WBIP can include new products or services, product or service improvements, marketing campaigns or distribution channels. WBIP summon customers who are mostly intrinsically motivated to contribute to the

\footnotetext{
$1 \mathrm{http}: / / \mathrm{ww} w \cdot$ ideastorm.com/

2 http://www.innocentive.com/

3 http://mystarbucksidea.force.com/
}

development of the products (Moore and Serva 2007; Janzik and Herstatt 2008; Reichwald and Piller 2009).

A recent study of successful WBIP showed that the focus of most platforms is to generate as many ideas as possible. User communication, incentive structures and platform functionality do not focus on supporting the creativity of the users in order to generate the best ideas possible. Since the capacity of companies is very limited when it comes to the adaption of external ideas, the focus of the platform operators has to change from an orientation towards quantity to an orientation towards idea quality in order to make WBIP more effective (Kipp, Wieck et al. 2013). This paper suggests user collaboration as a possible solution to this problem. This paper details the development of a web-based collaborative idea elaboration process that can be adapted to different kinds of WBIP. It aims to develop a structured tool-supported process to enable collaborative elaboration of ideas by participants on a WBIP. The goal of the process is to enhance an initial idea as it can be found on any current WBIP. During the collaboration process, the participants will structure the initial idea into the description of a relevant problem and a feasible detailed description of a possible solution to this problem. These parts (problem and solution description) resemble an elaborated version of the initial idea with a problem description that points out the relevance of the idea and a detailed solution description, which informs the first steps of a future implementation of the idea. In this paper, we show the development of the collaboration process design based on the Collaboration Process Design Approach and a pilot implementation of the process. The research questions answered in this paper are the following:

- How can a repeatable collaboration process improve the idea elaboration in WBIP?

- What is a possible technical implementation of the developed process?

- To which extend does the collaborative idea elaboration process increase idea quality?

The paper is structured as follows: Section 2 describes the process of designing the collaborative idea elaboration process. It explains how the collaboration process design approach (CoPDA) (Kolfschoten and De Vreede 2009) is used for the development of the process and how the consensual assessment technique (Amabile 1982) is used for the evaluation of the ideas resulting from the process. Section 3 displays the results of the proof of concept. Section 4 explains the limitations of this paper and section 5 summarizes the findings and points out the practical and theoretical contribution. 


\section{Development based on the collaboration process design approach}

In this section, the process of how to design an innovative collaborative idea elaboration process will be shown. This paper adheres to design science research guidelines, which aim to develop solutions to organizational and business problems through designing and evaluating novel artefacts. To achieve this, design research focuses on the creation of innovative and purposeful artefacts for a specified problem domain. Such artefacts include new constructs or prototypes, and new methods for their development. In the case of this paper, the artefact to be designed is a collaborative idea evaluation process. Following the design science guidelines by Peffers et al. (2007), we will first elaborate on the specific requirements for the success of the process, before the steps of the process will be detailed. The complete process was evaluated in three proof of concept workshops with 6 participants each, focusing on the elaboration of one idea per workshop. In order to develop the collaboration process, we choose collaboration engineering methodology, as it aims at "designing collaborative work practices for high-value recurring tasks, and deploying those designs for practitioners to execute for themselves without ongoing support from professional facilitators" (De Vreede and Briggs 2005). Kolfschoten and de Vreede (2009) provide a systematic five step approach for the design of collaboration processes. Figure 1 displays the collaboration process design approach, which we follow in our research.

According to Kolfschoten and De Vreede (2009) task diagnosis is the first necessary step to understand the environment as well as the goals of the collaboration process. The task diagnosis step takes a closer look at the collaboration tasks, the goals it should achieve as well as the deliverables of the process. The central goal of the collaborative idea elaboration process is the elaboration and improvement of an existing initial idea. This includes an assessment of the initial idea by the participants in the collaboration process as well as an augmentation of the idea by each user's comments and contributions. Since this process is supposed to be adoptable to most WBIP with the ideas that can be found on it, the process should not introduce new guide-

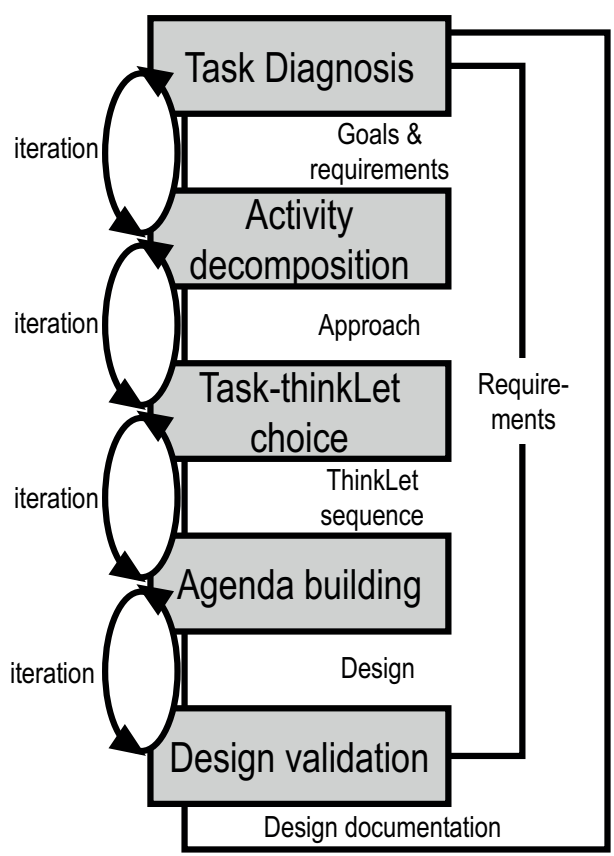

Figure 1: The collaboration process design approach (Kolfschoten and De Vreede 2009) lines or restrictions regarding the initial idea. Our earlier analysis of current WBIP (Kipp, Wieck et al. 2013) showed that most ideas posted on WBIP are usually not following a predefined structure and usually vary in length between 50 and 250 words with a low level of detail. This is the starting point for the initial ideas that is assumed for the development of the collaborative idea elaboration process.

The final elaborated idea should show a level of detail that allows organizations an easy assessment of the value and feasibility of the idea. Therefore, the problem description needs to point out the underlying problem from different perspectives and including a list of possible stakeholders. For the suggested solution, this means that it should include suggestions for possible idol projects (Who did something similar before?) or ideas of external service providers who could support the implementation of the idea. Ideally, the suggested solution already includes an estimate for the expected implementation cost or schedule.

The second step of the collaboration process design approach "activity decomposition" divides the process into smaller steps with clearly defined goals and results. This step is necessary to enable the collaboration engineer to select the appropriate tools and thinkLets for each activity (Briggs, De Vreede et al. 2001).

Figure 2 shows the sequence of necessary actions to achieve the collaboration goal of understandable and well elaborated ideas. The top of each block indicates the title of the activity. The figure also includes the pattern of collaboration for each activity. The first activity is problem extraction. In this activity, the collaborative goal is the generation of a problem description covering different aspects of the original problem. This activity creates a clear understanding of the problem that the group is going to solve during the collaboration process. The result is a textual description of different aspects of the problem. In the problem voting activity, the participants upvote or downvote on the previously posted problem aspects based on the perceived relevance for the idea. In the third step of the process "problem elaboration", the 
participants create one problem description based on the problem aspects that have been created in the first two steps. This achieves two important goals: The participants are forced to build consensus regarding the important aspects of the problem, and the idea is reduced and rewritten in a readable form that helps to convince others of the relevance of the problem. After the problem description is finished, the participants move on to generate a common solution description. This is also performed in three consecutive steps. In the "solution generation" activity, participants generate one rough outline of a possible solution each. These outlines are visible to each of the other participants. In the next step "solution selection" participants vote on the submitted solutions in order to identify the most promising one. This one selected solution will serve as a starting point for the collaborative elaboration of a final text that is performed in the "solution elaboration" activity.

In the "task thinkLet choice" step of the collaboration process design approach there is a thinkLet assigned to each activity. A thinkLet is a predefined pattern designed to achieve a defined collaboration goal. The selected thinkLets can be found in Table 1. The thinkLet selection is based on Briggs and de Vreede (2009).

Not every task could exactly be matched by the thinkLets defined by Briggs and de Vreede (2009). This made it necessary to make some changes to the original thinkLet descriptions with respect to the distributed environment of the collaboration process. The idea elaboration process consists of two phases with three very similar activities each. Both phases use the same thinkLets for their activities. The first step in each phase is the extraction of the problem/ solution using a modified version of the Popcornsort thinkLet. The modification we made was that the participants should assign a part of the original idea to the problem/solution or leave it unselected. There were no alternative buckets given to them. For the two activities problem/solution elaboration and concretion, the same OnePage thinkLet page is used.

The "Agenda building" step of the collaboration process design approach is very specific to the implementation of the collaboration process. Since the col-
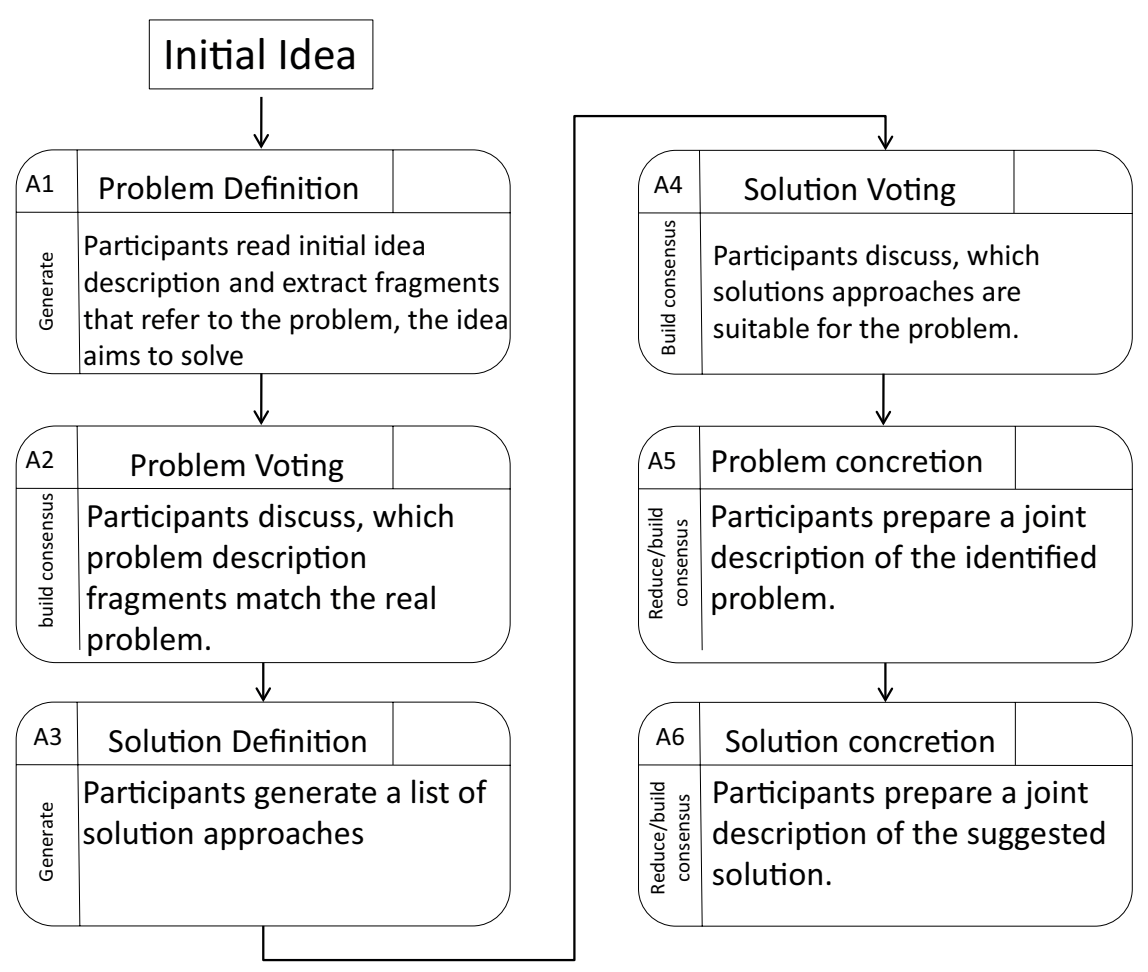

Figure 2: The collaborative idea elaboration process.

laborative idea elaboration process is to be implemented in a specialized software tool on WBIPs it would be necessary to include the software development process at this point of the collaboration process design approach. This is currently not explicitly supported by Kolfschoten and de Vreede. (2009) The future research section of this paper points out arguments for an adaptation of the collaboration process design approach, which cannot be covered in the scope of this paper.

In order to evaluate the interaction of the participants within the collaboration process developed above and its results, the following section will describe a serious of evaluation workshops conducted with university students and domain experts.

\section{Process evaluation workshops}

This paper develops a collaborative idea elaboration process. A good evaluation is crucial in order to validate the process and to guide future research. The evaluation of the process was carried out in three evaluation workshops with groups of German university students. Each group consisted of five students from different majors (economics, engineering, art and computer sciences). The collaborative idea elaboration process was set up in a local network on the group support system (GSS) ThinkTank. In order to control for any external influences, all participants were invited to the laboratory. This allowed the researchers to keep the communication of the participants closer to the environment than one would find on a WBIP. The group support system allows to follow the exact progress of the ideas made in the collaborative elaboration.

There are several different kinds of sources for results from the proof of concept: The first is the observation of the researchers during the workshops. This is a very important source for future revisions of the collaboration process. The researchers observe at which process points the participants use verbal discussions or other means of communication a toolbased process implementation on a website should support. The most important results are the original as well as the col- 
laboratively elaborated ideas. The quality of the original ideas are compared with the elaborated ones in an expert rating using Amabile's consensual assessment technique (Amabile 1982). This gives insight into the extent to which the collaborative idea elaboration process improves idea quality.

\subsection{Observation results}

The participants followed the steps according to the collaboration process design. The steps problem extraction and problem concretion worked exactly according to the planned process. The participants copied the relevant parts of the original ideas and agreed on their improvements by using the adding and editing functionalities of the group support system. In the following steps of extracting and concreting the possible solutions, the participants very often used communication outside of the text-based group support system. Most of them used direct face-to-face discussions during the solution concretion phase. One group even used a whiteboard to visualize relationships among concepts and to develop a shared understanding of the problem solution. This shows us that just text based collaboration is inconvenient for high creativity tasks. Future revisions of the process, as well as the tools used for the process implementation, need to support additional ways of communication, such as direct chat, separate discussions or graphic display of ideas, to support shared understanding among the participants.

\subsection{Idea quality evolution}

The evolution of the idea documents shows the contribution a collaborative effort can make. While the problems of the initial ideas were mostly adopted, new possible solutions were found in the process. While not all of the resulting solutions could be implemented easily, well elaborated solutions can help to "sell" the idea to people and make them aware of how they could profit from the implementation. This shows that the structured collaborative process not only enables the participants to combine their knowledge and ideas, but also to create new value by building on the ideas of others. This is an important hint towards structured collaboration as a tool for successful elaboration of simple ideas.

In the proof of concept, three ideas were collaboratively elaborated upon using the process described above. This section elaborates on the influence of collaborative elaboration on the quality of ideas. In order to do so, we used the consensual assessment technique by Amabile (1982). It uses multi-dimensional expert ratings to assess the quality of ideas. In this case, we surveyed a jury of five university employees with at least three years of job experience. This ensures that the jury members are capable of evaluating improvement ideas for the university environment, as they were developed by the workshop participants. The evaluation survey assessed five distinct items to evaluate different dimensions of idea quality. The items included in the survey were originality; feasibility; benevolence; simplicity, and completeness. Each item was operationalized by one claim. The jury members were asked to express their agreement on each claim on a 5-step Likert scale. They did not know which of the ideas were initial or elaborated and evaluated the ideas in random order.

Every item rating was valued with a score from 1 (lowest) to 5 (highest). The first result of the expert rating is that the overall rating of each idea improved in the course of the collaboration process. Table 2 shows the overall scores for the initial, as well as the elaborated, ideas.

Another important finding from the expert rating was that the improvement rates were not equally distributed among the items. The advancements for completeness and originality are in general very high; the average improvements on feasibility and simplicity are instead negative, i.e., the elaborated ideas are mostly rated worse for both items than the initial ideas.

The successful improvements of the items originality and completeness coincide with the goals of the collaborative approach: To create a better elaborated version of the ideas using the creativity and originality of multiple participants.

The decline of the ratings for feasibility and simplicity can be explained by the higher complexity of the elaborated ideas. As multiple people collaborate and contribute their insights to the idea, more aspects are included into the solution. Therefore, the idea becomes more complex (negative simplicity) and more difficult to implement (negative feasibility).

\begin{tabular}{|c|c|c|c|c|c|c|c|c|c|c|c|c|}
\hline \multirow[t]{2}{*}{ Idea } & \multicolumn{6}{|c|}{ Initial } & \multicolumn{6}{|c|}{ Elaborated } \\
\hline & 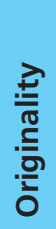 & 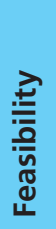 & 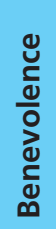 & 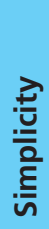 & 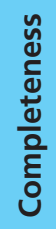 & $\begin{array}{l}\bar{\Xi} \\
\stackrel{0}{0}\end{array}$ & 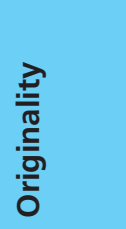 & 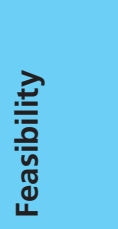 & 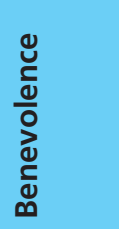 & 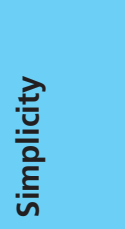 & 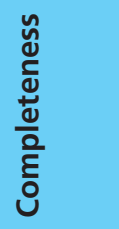 & $\begin{array}{l}\overline{\stackrel{0}{0}} \\
\stackrel{\circ}{\circ}\end{array}$ \\
\hline 1 & 13 & 15 & 19 & 14 & 8 & 69 & $15(+2)$ & $12(-3)$ & $21(+2)$ & $16(+2)$ & $13(+5)$ & $77(+8)$ \\
\hline 2 & 14 & 14 & 25 & 22 & 13 & 88 & $18(+4)$ & $14(+0)$ & $24(-1)$ & $21(-1)$ & $19(+6)$ & $96(+8)$ \\
\hline 3 & 13 & 11 & 13 & 15 & 9 & 64 & $16(+3)$ & $9(-2)$ & $17(+4)$ & $11(-4)$ & $11(+2)$ & $64(+3)$ \\
\hline
\end{tabular}

Table 2: Idea evaluation results. 


\section{Limitations}

This section summarizes the threats to the validity of the work. The internal validity of the evaluation could be threatened by the fact that we analyzed the resulting ideas but not the communication of the participants. The participants operated the process in the presence of the observer though without recording of the oral communication. The participants were encouraged to write down their questions and issues through the use of the group support system. However, we did not prevent oral communication in the evaluation, which is a limitation of this study.

Regarding external validity, the major concern is the generalizability of the results. Indeed the idea elaboration process was pilot tested only three times with university students. We tried to limit this effect by selecting a topic in which students can be considered as experts and therefore suitable for the collaborative work. Due to the diversity of ideas and idea communities, we cannot claim that the results are representative for all idea communities. Further, the involved participants could have had an effect on the idea elaboration. This study is a first step to validate the collaborative idea elaboration process. To strengthen the results, other ideas with other participants should be analyzed.

\section{Discussion and conclusion}

The collaboration process developed in this paper is an important step for successful collaborative idea elaboration on WBIP. The process was developed and evaluated following well established methodology from the field of Collaboration Engineering, especially the collaboration design approach by Kolfschoten and de Vreede. The article shows first results with a prototypal evaluation with students.

Collaboration Engineering and the collaboration process design approach provided the methodology for the development of collaborative processes. We used this body of knowledge to develop and pilot our collaborative idea elabo- ration process. The process is based on the separate identification and elaboration of the idea's underlying problem and its suggested solution by a group of idea stakeholders with knowledge in the idea's basic topic. The evaluation by a jury of experts suggests that the overall quality of the idea improves during the collaboration process. The analysis shows an increase in quality, especially for the items elaboration and originality. The contribution of this paper can be divided into theoretical and practical aspects. The theoretical aspect is the combination of different approaches from Information Systems, Collaboration Engineering and Innovation Management. Combining these three fields enables an increase in idea quality and therefore strengthens the Open Innovation approach. On the other hand, the practical perspective describes a step towards the implementation of collaboration tools on WBIP, so that platform providers could foster collaboration as well as an increase of idea quality on their platforms. In summary, you can say that the results are based only on a small sample of ideas and few expert ratings, but they do indicate an improvement in the overall idea quality and especially in the elaboration and originality items. This shows that the collaborative idea elaboration process is a promising approach to improve idea quality. Besides, the results also demonstrate that the ideas generated in our collaboration process tend to become more complex than the initial ideas. In future revisions of the process, one focus point will be to find an optimal degree of complexity in the elaborated versions of the ideas.

This paper lays the foundation for future research in user collaboration for WBIP.

\section{Future Research}

One aim of the ongoing research project this study is part of, is the implementation of the collaborative idea elaboration process on a WBIP. This integration requires the development of specialized collaboration tools.

Currently the selection of appropriate collaboration tools is part of the "agenda building" step of the collaboration pro- cess design approach. The reason for positioning the tool selection in the agenda building phase is, that in common same place/same time collaboration workshops there are many tangible tools like whiteboards, PowerPoint presentations, sticky notes, off-the-shelf group support systems etc. available and the tool choice is trivial for most collaboration activities once the thinkLet (already determined in step three) and the available resources (determined in step one) are given. Additionally the agenda building step includes the phrasing of exact instructions and inspirational questions, which are usually very closely related to the tool used for communicating and processing the results. For this reason the exact wording by Kolfschoten and de Vreede (2009) is very short and generic:

"The questions and instructions should be [...] detailed by specifying the key information regarding issues such as the categories, voting criteria, voting scale, topics, prompts, and the (GSS) tools used"(Kolfschoten and De Vreede 2009)

This approach reaches its limits when it comes to different place/different time online collaboration on web-based platforms and when no off-the-shelf group support systems can be used. When the collaboration process needs to be integrated into an existing web-based platform and all communication between the collaboration process participants is done on the platform, a new customized collaboration tool needs to be developed and implemented. This implementation of new collaboration tools is currently not directly supported by any information given in the collaboration process design approach.

The current solution to combine the use of the collaboration process design approach and a software development process is to use the tool capabilities defined in the selected thinkLets as requirements for the software development process. Additional software requirements can be deducted from the result of the agenda building step of the CoPDA. While this approach to developing specialized collaboration tools is feasible, the decoupling of the collaboration process design and the tool design comes with some disadvantages. The most impor- 
tant one is the loss of the iterative nature of the collaboration process design approach that allows the collaboration engineer to modify previously defined details of the process design based on decisions or restrictions that came up in later steps of the design process. Another problem is that the final step of the collaboration process design approach cannot be properly executed without a working toolset for the collaboration process design.

Therefore, we suggest a modification of the collaboration process design approach in order to account for collaboration processes that require the development of completely new software tools supporting the collaboration process.

Additional future research projects could focus on transferring the collaborative idea elaboration process developed in this paper from a university context into an enterprise environment as the challenges of integrating a tool-based collaboration process into fixed business processes will certainly differ from the challenges faced at the introduction of the tool and process into a university setting.

\section{Literatur}

Amabile, T. M. (1982). "Social psychology of creativity: A consensual assessment technique." Journal of Personality and Social Psychology - PSP 43(5): 997-1013.

Bretschneider, U., M. Huber, et al. (2008). Community for Innovations: Developing an Integrated Concept for Open Innovation. IFIP 8.6 Conference. Madrid.

Briggs, R. O. and G.-J. de Vreede (2009). ThinkLets - Building Blocks for Concerted Collaboration. Omaha.

Briggs, R. O., G. De Vreede, et al. (2001). ThinkLets: achieving predictable, repeatable patterns of group interaction with group support systems (GSS). System Sciences, 2001.
Proceedings of the 34th Annual Hawaii International Conference on, IEEE.

De Vreede, G.-J. and R. O. Briggs (2005). Collaboration Engineering: Designing Repeatable Processes for High-Value Collaborative Tasks. 38th Hawaii International Conference on System Sciences.

Janzik, L. and C. Herstatt (2008). Innovation Communities: Motivation and Incentives for Community Members to contribute. IEEE International Conference on Management of Innovation and Technology (ICMIT). Bangkok.

Kipp, P., E. Wieck, et al. (2013). 12 Years of GENEX Framework: What did Practice Learn from Science in Terms of Web-Based Ideation? 11. Internationale Tagung Wirtschaftsinformatik. Leipzig.

Kolfschoten, G. and G.-J. De Vreede (2009). "A Design Approach for Collaboration Processes: A Multi-Method Design Science Study in Collaboration Engineering." Journal of Management Information Systems 26(1): 225-256

Kolfschoten, G. L. and G.-J. De Vreede (2009). "A Design Approach for Collaboration Processes: A Multimethod Design Science Study in Collaboration Engineering." Journal of Management Information Systems 26(1): 225-256.

Moore, T. D. and M. A. Serva (2007). Understanding Member Motivation for Contributing to Different Types of Virtual Communities: A Proposed Framework. ACM SIGMIS CPR conference on Computer personnel research: The global information technology workforce, St. Louis, MO, USA.

Peffers, K., T. Tuunanen, et al. (2007). "A Design Science Research methodology for Information Systems Research." Journal of Management Information Systems 24(3): 45-77.

Reichwald, R. and F. Piller (2009). Interaktive Wertschöpfung - Open Innovation, Individualisierung und neue Formen der Arbeitsteilung. Wiesbaden, Gabler.

von Hippel, E. (2005). Democratizing Innovation. Cambridge, MA, The MIT Press.
1 Philipp Kipp ist Diplom-Wirtschaftsinformatiker und arbeitet als wissenschaftlicher Mitarbeiter im Fachgebiet Wirtschaftsinformatik der Universität Kassel.

E-Mail: philipp.kipp@uni-kassel.de

2 Eva Bittner ist Diplom-Kauffrau und arbeitet als wissenschaftliche Mitarbeiterin im Fachgebiet Wirtschaftsinformatik der Universität Kassel.

E-Mail: eva.bittner@uni-kassel.de

3 Dr. rer. pol. Ulrich Bretschneider arbeitet als Wissenschaftlicher Mitarbeiter am Fachgebiet Wirtschaftsinformatik der Universität Kassel.

E-Mail: Ibretschneider@uni-kassel.de

4 Prof. Dr. Jan Marco Leimeister ist Leiter des Fachgebiets Wirtschaftsinformatik und Lehrstuhlinhaber des Lehrstuhls für Informationssysteme an der Universität Kassel.

E-Mail: leimeister@uni-kassel.de
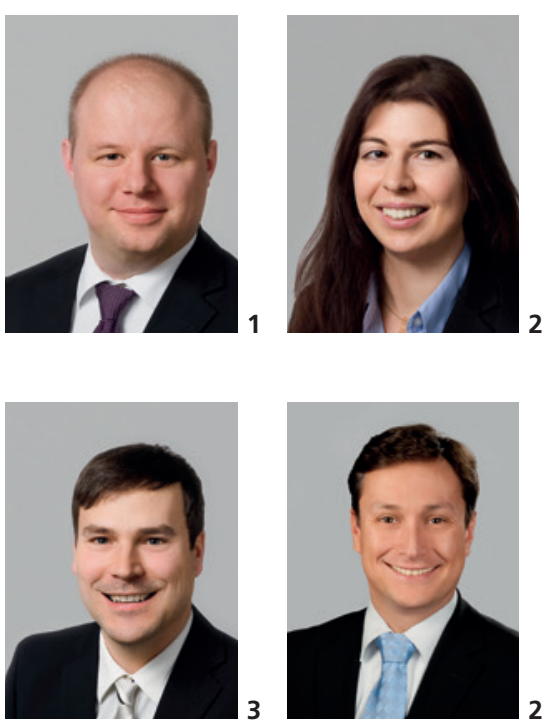